\title{
PKM Handicraft Limbah Kain Handuk "Kanta Craft” Milik Penyandang Cacat Di Surabaya
}

\author{
Ayun Maduwinarti ${ }^{*}$, Sri Andayani² \\ 1,2 Fakultas Ilmu Sosial dan Ilmu Politik, Universitas 17 Agustus 1945 \\ * Penulis Korespondensi: E-mail: ayunmaduwinarti@untag-sby.ac.id
}

\begin{abstract}
Competition in the handicraft craft industry is very tight. One of the SMEs engaged in handicrafts in Surabaya is the "KANTA CRAFT" owned by the handicapped, which is engaged in the utilization and processing of towel cloth patchwork combined with varieties of fabrics to make various handicrafts. The purposes of this activity are the identification of partner problems, the purchase of machinery/ equipment as well as training/assistance in business management and marketing. Problems: 1) Limited product results and slow production process 2) Limited ability/skills in using machinery and equipment 3) Business, Marketing and Bookkeeping have not been managed properly 4) Marketing of product results is still local and does not yet have marketing media. The Implementation Method is carried out by way of Identifying partner problems, Participatory Learning, Learning by Doing Method.The solutions provided: 1 . Procurement of sewing machines with complete types 2 . Skill training using tools and machines. 3. Business Management Training and Assistance, Marketing and Bookkeeping 4. Technical Training and Marketing Strategy, Brochure and Banner Manufacturing.
\end{abstract}

Keywords: Handicraft from towel cloth patchwork, "KANTA CRAFT"

\begin{abstract}
Abstrak
Persaingan di industri kerajinan tangan sangat ketat. Salah satu UKM yang bergerak di bidang kerajinan tangan di Surabaya adalah "KANTA CRAFT" milik penyandang disabilitas, yang bergerak di bidang pemanfaatan dan pengolahan kain perca kain handuk yang dikombinasikan dengan berbagai macam kain untuk membuat berbagai kerajinan tangan. Tujuan dari kegiatan ini adalah identifikasi masalah mitra, pembelian mesin/ peralatan serta pelatihan/pendampingan dalam manajemen bisnis dan pemasaran. Masalah: 1) Hasil produk yang terbatas dan proses produksi yang lambat 2) Kemampuan/ keterampilan terbatas dalam menggunakan mesin dan peralatan 3) Bisnis, Pemasaran dan Pembukuan belum dikelola dengan baik 4) Pemasaran hasil produk masih lokal dan belum memiliki media pemasaran. Metode Implementasi dilakukan dengan cara Mengidentifikasi masalah mitra, Pembelajaran Partisipatif, Pembelajaran dengan Melakukan Metode. Solusi yang diberikan: 1. Pengadaan mesin jahit dengan tipe lengkap 2. Pelatihan keterampilan menggunakan alat dan mesin. 3. Pelatihan dan Bantuan Manajemen Bisnis, Pemasaran dan Pembukuan 4. Pelatihan Teknis dan Strategi Pemasaran, Brosur dan Pembuatan Banner.
\end{abstract}

Kata kunci: Kerajinan Tangan dari Kain Perca, "KANTA CRAFT"

\section{PENDAHULUAN}

\section{Latar Belakang}

Saat ini dunia usaha sudah semakin berkembang. Kemunculan banyak UMKM di berbagai usaha merupakan fenomena yang biasa. Persaingan industri perajin handicraft sangat ketat. Surabaya memiliki banyak UMKM yang beraneka ragam mulai dari Handicraft maupun usaha kuliner. Salah satu UKM yang bergerak di bidang kerajinan Handicraft di Kecamatan 
Benowo adalah "KANTA CRAFT" milik penyandang cacat ini bergerak di bidang pemanfaatan dan pengolahan limbah kain handuk perca yang dipadu dengan berbagai macam kain untuk dibuat berbagai handicraft. Keterbatasan fisik tidak mematikan kreatifitasnya untuk menyulap limbah perca kain handuk dan jenis kain lainnya menjadi kreasi produk-produk handicraft yang bernilai tinggi.

Limbah/perca kain handuk dan jenis kain lainnya selama ini sering dipandang remeh. Orang sering membuangnya ke tempat sampah atau membakarnya. Mungkin bagi sebagian orang bekas perca kain handuk tidak bisa digunakan lagi untuk barang yang berharga. Namun berbeda dengan sosok Bapak Ahmadi dan istrinya keduanya difabel. Keterbatasan yang dimiliki tidak mematikan ide kreatifnya. Dengan kreatifitasnya perca handuk dan jenis kain lainnya ini diubah menjadi produk serbet gantung, tempat tisue, tas dan dompet yang bagus dan benilai ekonomis.. Nama usahanya "KANTA CRAFT". Hasil produksinya berupa : Serbet gantung, tempat tisue, tas dan dompet. Alamat: Kandangan Jaya 3 No. 3 Kecamatan Benowo, Kota Surabaya.
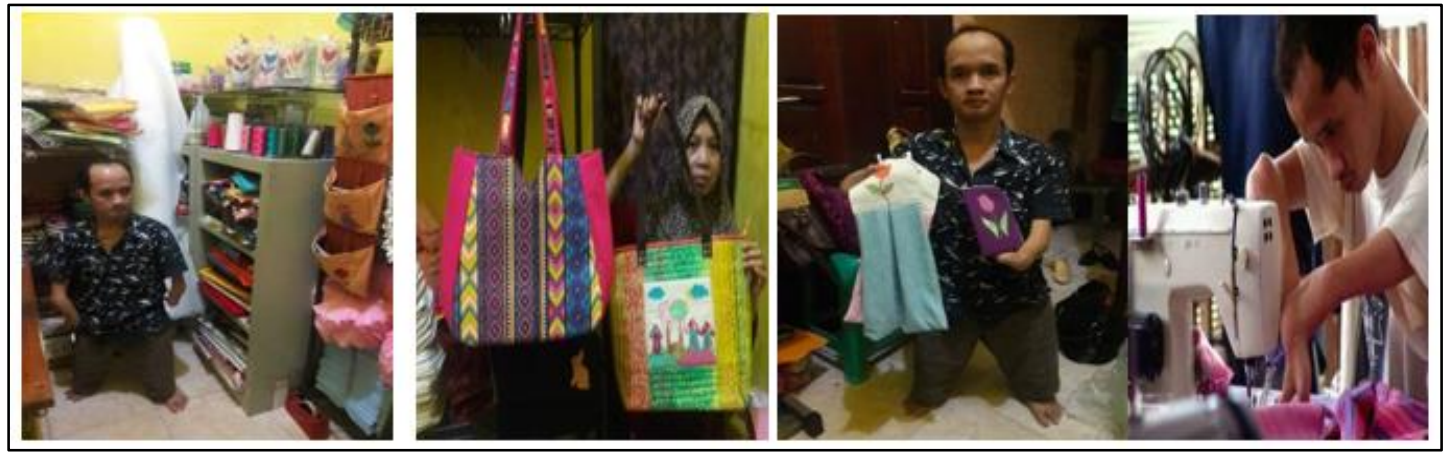

Gambar 1. Pemilik Kanta Craft

(Sumber : Data Primer)

Peralatan produksi yang dimiliki dan digunakan saat ini masih sangat sederhana, menggunakan satu mesin jahit yang sederhana sehingga hasil produksi terbatas dan proses produksi lambat.

\section{Bahan baku dan Peralatan yang di gunakan saat ini}

a. Bahan terdiri dari Limbah Kain (Perca) handuk warna warna, Benang, kain dalaman tas.

b. Peralatan terdiri dari gunting, Mesin Jahit.

2. Alur Proses pembuatan Serbet/Tas /Dompet / Handicraft Perca.

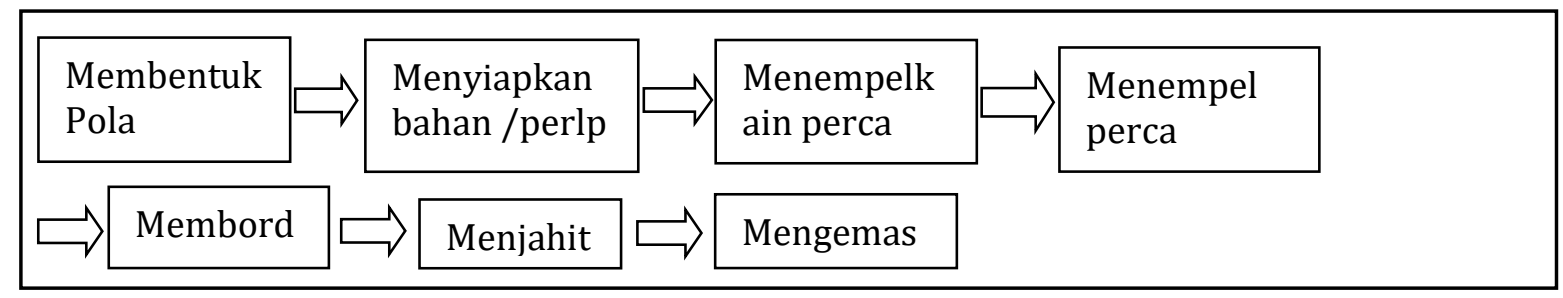

Gambar 2. Alur Proses produksi

(Sumber: Data primer (diolah penulis)) 
Harga jual produknya bervariasi antara Rp. 5.000,00 sampai Rp. 200.000,00 tergantung besar kecilnya produk dan tingkat kesulitan produknya. Pemasaran dititipkan di Toko, atau di pameran, pesanan, di acara-acara PKK, Pengajian.

\section{Permasalahan UKM Kanta Craft}

Dari uraian di atas diidentifikasikan beberapa permasalahan yang dihadapi oleh Kanta Craft adalah sebagai berikut :

1. Hasil produk terbatas dan proses produksi lambat, hal ini disebabkan karena terbatasnya mesin yang dimiliki hanya satu dan masih sangat sederhana. Dampaknya tidak bisa memenuhi beberapa pesanan souvenir atau handicraft.

2. Masih terbatasnya kemampuan dan ketrampilan dalam menggunakan mesin dan peralatan.

3. Usaha, Pemasaran dan Pembukuan belum dikelola secara baik.dititipkan di Toko, atau di pameran, pesanan, di acara-acara PKK, Pengajian.

4. Belum memiliki media pemasaran.

\section{Tujuan Kegiatan}

Tujuan kegiatan dari pendampingan dan kegiatan Pengabdian masyarakat ini adalah:

a. Agar UKM Kanta Craft bisa memenuhi pesanan dalam jumlah yang banyak dan proses produksi lebih cepat, maka dilakukan pembelian Mesin dengan spesifikasi yang lengkap.

b. Untuk mengatasi masalah terbatasnya ketrampilan penggunaan mesin dan alat maka diadakan pelatihan ketrampilan.

c. Memberikan pelatihan dan pendampingan pengelolaan usaha, strategi pemasaran dan pembukuan.

d. Pengadaan X Banner, Brosur dan kartu nama sebagai media promosi dalam upaya meningkatkan jumlah produk yang terjual.

\section{METODE PELAKSANAAN}

Metode pelaksanaan kegiatan ini adalah sebagai berikut:

\section{a. Melakukan identifikasi beberapa permasalahan yang dihadapi oleh mitra UKM KANTA CRAFT}

Identifikasi dilakukan dengan survey awal, wawancara dengan mitra, dan observasi kegiatan yang dilakukan UKM Kanta Craft untuk mengetahui permasalahan yang paling mendesak.

Berdasarkan hasil identifikasi beberapa permasalahan yang dihadapi UKM KANTA CRAFT, selanjutnya di tentukan beberapa masalah yang krusial yang harus segera diatasi diantaranya : Hasil produk terbatas dan proses produksi lambat, masih terbatasnya kemampuan dan ketrampilan dalam menggunakan mesin dan peralatan, Usaha, Pemasaran dan Pembukuan belum dikelola secara baik dan pemasaran hasil produk masih lokal dan belum memiliki media pemasaran.

a. Metode pendekatan yang dilakukan adalah:

- Metode Learning By Doing. Dalam metode ini perajin dalam mengikuti pelatihan tidak harus dengan meninggalkan pekerjaannya. Akan tetapi dalam proses pelatihan bisa dilaksanakan bersamaan dengan saat perajin melakukan pekerjaannya. Dengan demikian diharapkan pelatihan yang diberikan dapat diterima dan dilaksanakan dengan baik. 
- Metode Partisipatif, yang diterapkan dalam proses pelatihan dan pendampingan ini dengan melibatkan secara aktif perajin secara langsung dalam aplikasinya.

Adapun Alur pikir pendampingan dan pelatihan adalah sbb:

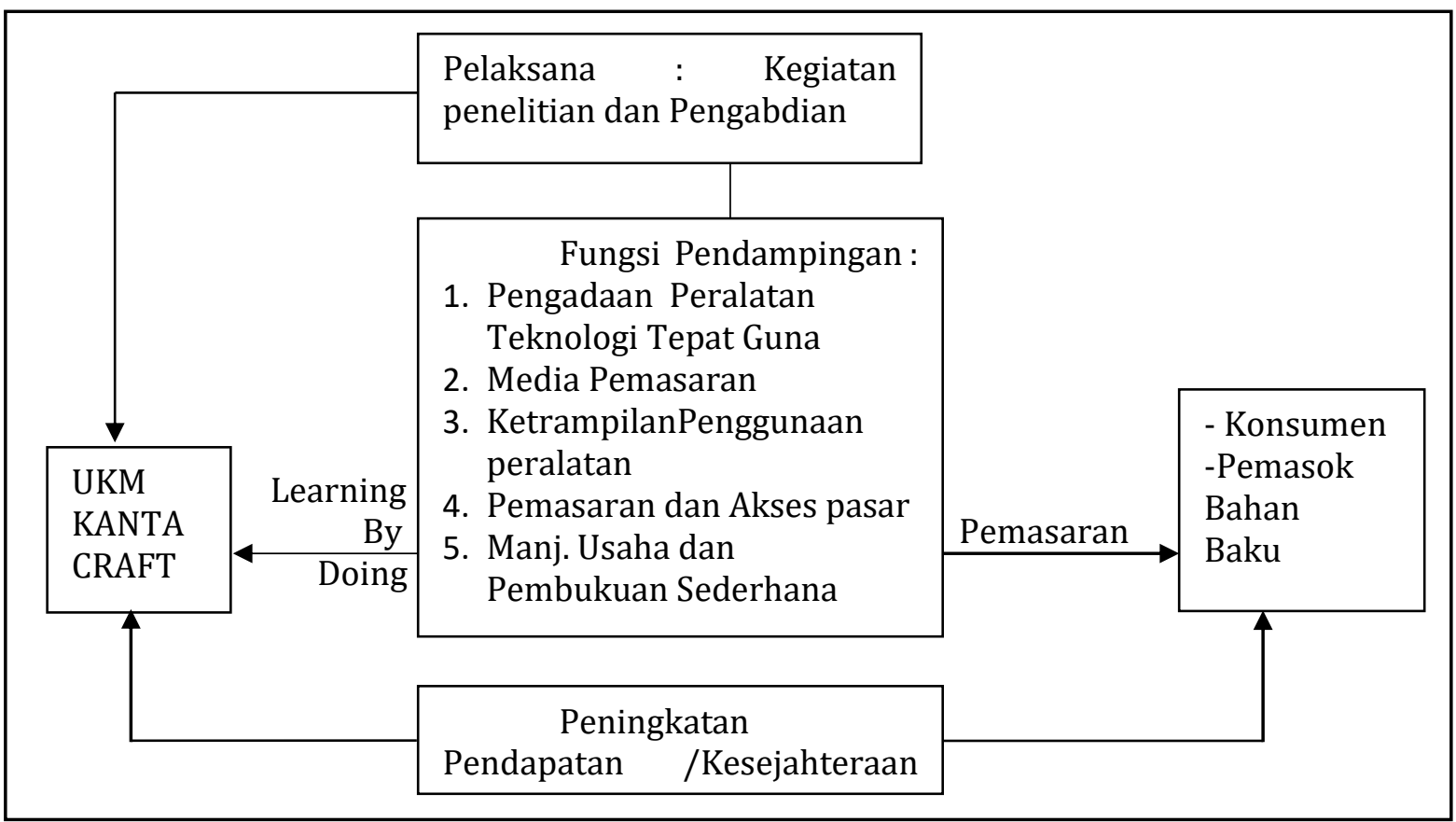

Gambar 3. Alur Pikir Pendampingan dan Pelatihan

\section{HASIL dan PEMBAHASAN}

Kegiatan ini diawali dengan koordinasi dengan UKM Kanta Craft berkaitan dengan pelaksanaan kegiatan pelatihan dan pendampingan serta Introdusir peralatan. Selanjutnya dilaksanakan survey untuk pengadaan barang peralatan yang dibutuhkan oleh UKM Mitra. Pelatihan dan pendampingan, dengan menggunakan dana dari Program Pengabdian masyarakat ( PKM) Universitas 17 Agustus 1945 Surabaya.

Adapun hasil dari kegiatan tersebut adalah sebagai berikut:

Tabel 1 Hasil yang telah dicapai pada pelaksanaan pelatihan dan pendampingan UKM Kanta Craft

\begin{tabular}{llrl}
\hline No & \multicolumn{2}{c}{ Rencana } & \multicolumn{1}{c}{ Realisasi } \\
\hline 1 & Rencana & Teknis & Pengadaan 1unit mesin untuk UKM Kanta Craft, mesin jahit \\
& pengadaan & TTG & ini bisa diatur kecepatannya, fungsi lengkap, sehingga \\
& pengadaan mesin & mampu memproduksi dalam jumlah banyak dalam waktu \\
& & yang cepat, bervariasi sehingga mampu memenuhi pesanan \\
& & konsumen.
\end{tabular}




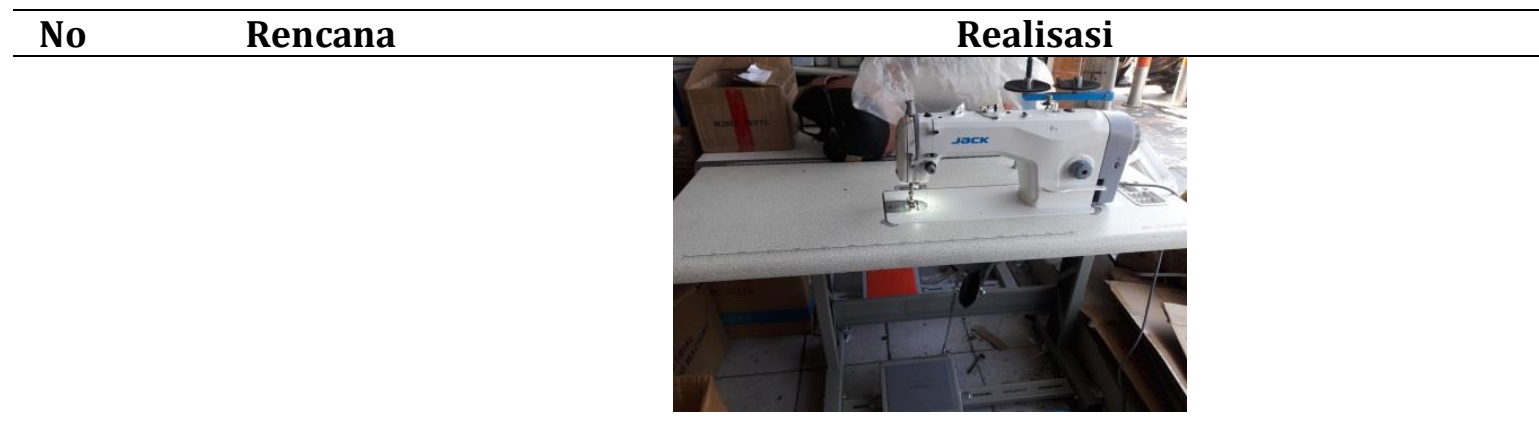

2 Memberikan Pelatihan UKM Kanta Craft dan Karyawannya mampu ketrampilan menjalankan/menggunakan mesin yang baru dan penggunaan mesin dan memelihara mesin dengan baik. peralatan

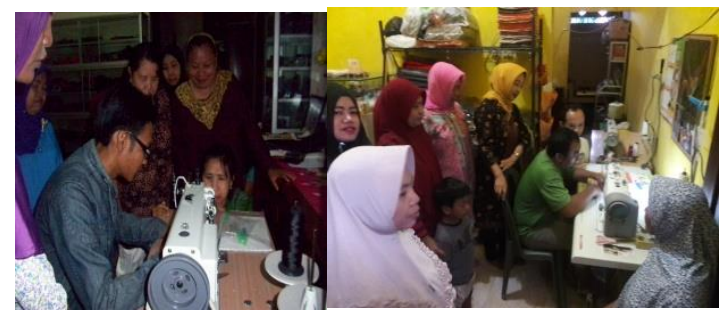

3 Memberikan pelatihan dan pendampingan pengelolaan pemasaran pembukuan usaha,
dan
Dengan adanya pelatihan dan pendampingan pengelolaan usaha dan pembukuan, UKM Kanta Craft mampu memisahkan antara kebutuhan pribadi dan usahanya. Bisa membuat pembukuan sederhana, setiap kali transaksi dilakukan dibukukan dengan tertib dan rapi.

Disamping itu UKM Kanta Craft juga mampu mengembangkan pemasaran, dengan memanfaatkan media social seperti instagram, facebook, Whatsup dll, sehingga yang selama ini sebatas pemasaran lokal sekarang sudah mampu menjual ke luar Surabaya

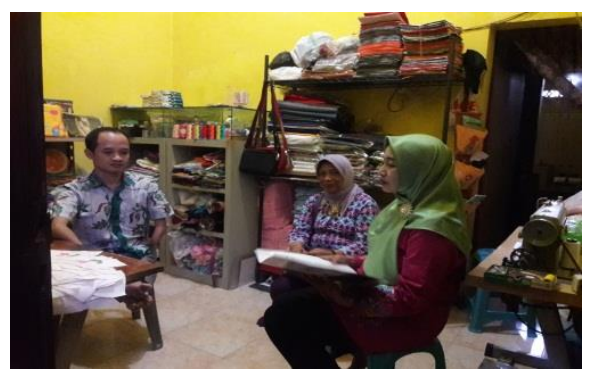

\footnotetext{
4 Pengadaan $\mathrm{X}$ Banner, Tersedianya X Banner, kartu nama dan brosur sebagai kartu nama dan brosur media pemasaran sebagai media Promosi
} 


No Rencana $\quad$ Realisasi

\section{KESIMPULAN}

\section{Kesimpulan}

Berdasarkan kegiatan pelatihan dan pendampingan yang telah dilaksanakan pada UKM Kanta Craft maka dapat disimpulkan hal-hal sebai Berikut :

1. Kegiatan Pengabdian Masyarakat ( PKM ) Membantu Kelompok Usaha Kecil terutama pengembang Ekonomi kreatif seperti Handicraft dari kain Perca handuk untuk tumbuh dan berkembang serta menjaga Lingkungan Hidup dan Mengembangkan Ekonomi Kreatif di Surabaya.

2. Pemilik dan karyawan UKM Kanta Craft sangat antusias dan serius dalam mengikuti pelatihan teknis dan Pemasaran serta manajemen Usaha yang diberikan.

3. Dengan adanya kegiatan pengabdian masyarakat (PKM) yang memfasilitasi mesin dan Peralatan Perajin Handicraft Kanta Craft mampu memenuhi permintaan konsumen.

4. Media promosi yang digunakan dengan memanfaatkan media social, $\mathrm{X}$ Banner, Brosur dan kartu nama, maka Kanta Craft lebih dikenal oleh masyarakat dan omset produknya semakin meningkat.

5. Bagi Perguruan Tinggi sebagai bentuk pengabdian Masyarakat yang jelas nyata membantu masyarakat UKM yang membutuhkan.

\section{Saran}

Adapun saran yang kami usulkan diantaranya adalah :

1. KegiatanPengabdian masyarakat (PKM) terus dilakukan oleh Universitas 17 Agustus 1945 Surabaya sebagai kepedulian terhadap masyarakat khususnya memfasilitasi Usaha Mikro dan Kecil yang mempunyai prospek usaha yang bagus.

2. Kegiatan ini sebaiknya menunjang kegiatan pengembangan Ekonomi Kreatif 


\section{DAFTAR PUSTAKA}

Buchari, A., 2004. Manajemen Pemasaran Dan Pemasaran Jasa. Alfabeta, Bandung Departemen Perdagangan, 2007

Fandy Tjiptono. 2008. Strategi Pemasaran, Edisi 3, Penerbit Andi Yogyakarta.

Kotler, Philip dan Kevin Lane. 2009. Manajemen Pemasaran, Edisi 13, Penerbit Erlangga, Jakarta.

Lucas, Ferrel and Luck David. 1994. Strategic Marketing Management "Text and cases", College Division South Western Publishing Co.

Tambunan, T. 2002. Usaha Kecil dan Menengah di Indonesia, Beberapa Isu penting, Salemba, Jakarta.

Noviyanto. (2020). Strategi Memperluas Pangsa Pasar. Diambil kembali dari KOINWORKS: https://koinworks.com/blog/strategi-memperluas-pangsa-pasar/

Uprint.id. (2020, 9 9). Uprint.id. Diambil kembali dari Uprint.id percetakan online indonesia: https://uprint.id/blog/industri-kreatif-yang-menguntungkan/ 